Manuel Quiroga, Teorías del imperialismo y marxismo en el socialismo francés temprano: el caso de Paul Louis (1896-

1907) / Theories of imperialism and Marxism in the early French socialism: the case of Paul Louis (1896-1907), Revista Izquierdas, 27, abril 2016, ISSN 0718-5049, pp. 342-367

\title{
Teorías del imperialismo y marxismo en el socialismo francés temprano: el caso de Paul Louis (1896-1907)
}

Theories of imperialism and Marxism in the early French socialism: the case of Paul Louis (1896-1907)

\author{
Manuel Quiroga Soto*
}

\footnotetext{
* Argentino, Licenciado en Historia, Becario Doctoral del CIECS-CONICET en Córdoba, Programa de Historia Contemporánea, manuelquirogasoto@gmail.com
} 
Manuel Quiroga, Teorías del imperialismo y marxismo en el socialismo francés temprano: el caso de Paul Louis (18961907) / Theories of imperialism and Marxism in the early French socialism: the case of Paul Louis (1896-1907), Revista Izquierdas, 27, abril 2016, ISSN 0718-5049, pp. 342-367

\section{Resumen}

En este artículo nos proponemos acercarnos al estudio de las teorías del imperialismo y las características del marxismo en el Socialismo Francés temprano, a través del estudio de un autor particular: Paul Louis (1872-1948), militante de origen Blanquista que desarrolló una vasta obra escrita a lo largo de su vida política. Nuestro primer problema es cuáles son las características específicas de sus análisis del colonialismo/imperialismo: los fundamentos económicos del fenómeno, su caracterización de los distintos países imperialistas y sus conclusiones políticas; vinculado a esto, analizamos su posición frente a algunos debates generales del socialismo de la época: sus posiciones frente al revisionismo y la participación ministerial de los socialistas, la huelga general, la Revolución Rusa de 1905, y la forma de gobierno republicana. Este análisis interno de la producción de Paul Louis será explicado también en el marco de los debates sobre estos tópicos que atravesaron el socialismo francés como un todo, así como las organizaciones políticas en que participó y la Segunda Internacional, para ser capaces de establecer con qué otras posiciones tenían afinidad, y cómo se situaban las mismas en el marco de la disputa de fracciones a nivel tanto nacional como internacional. Nuestra hipótesis es que Paul Louis articuló una visión original del imperialismo vinculado estrechamente a los cambios políticos de su tiempo, desde unos análisis tempranos más vinculados a una serie de herencias republicanas, pasando por un análisis riguroso del imperialismo como fase del capitalismo que influyó en Lenin, hasta una fase final donde se convirtió en una suerte de portavoz partidario sobre el tema, volviendo a una posición más propagandística. A su vez, a partir de 1905 articuló una visión propia del Marxismo que cuestionó varios aspectos de la ortodoxia del Guesdismo, la corriente marxista predominante del Socialismo Francés.

Palabras Clave: Socialismo, Colonialismo, SFIO, Paul Louis, Segunda Internacional, Imperialismo

Recibido: 8 diciembre 2015

Aceptado: 24 enero 2016

\begin{abstract}
In this article we intend to approach the study of the theories of imperialism and the specific characteristics of Marxism in early French Socialism, through the study of a particular author: Paul Louis (1872-1948), a militant of Blanquist origin that wrote a vast amount of work during his political life. Our first concerns are the specific features of his analysis of colonialism and imperialism: the economic foundations of the phenomenon, his characterization of the different imperialist countries and his political conclusions; tied to this, we analyze his position on some general debates of the socialism of that time: His standings on revisionism and socialists' ministerial participation, the general strike, the Russian Revolution of 1905, and the Republican form of government. This internal analysis of Paul Louis' work will be explained also in the framework of the debates over these topics that ran through French Socialism as a whole, as well as the political organizations in which he participated and the Second International, to be able to establish to which other positions they were close, and where were they placed in the fractional disputes on both national and international levels. Our hypothesis is that Paul Louis articulated an original vision of imperialism closely related to the political changes of his time, from some early analyses more related to a series of republican legacies, going through a rigorous analysis of imperialism as a phase of capitalism that influenced Lenin, until a final phase where he became a sort of party spokesman on the subject, returning to a more propagandistic stance. At the same time, from 1905 onwards he formed his own vision of Marxism that questioned many aspects of Guesdist orthodoxy, the predominant Marxist current of French Socialism.
\end{abstract}

Keywords: Socialism, Colonialism, SFIO, Second International, Paul Louis, Imperialism 
Manuel Quiroga, Teorías del imperialismo y marxismo en el socialismo francés temprano: el caso de Paul Louis (18961907) / Theories of imperialism and Marxism in the early French socialism: the case of Paul Louis (1896-1907), Revista Izquierdas, 27, abril 2016, ISSN 0718-5049, pp. 342-367

\section{Introducción}

En el presente artículo pretendemos abordar algunos de los principales debates y posiciones sobre el análisis del imperialismo en el socialismo francés, así como de algunos temas relacionados con la teoría marxista y la práctica política de los partidos socialistas que tuvieron estrecha relación con el problema del imperialismo en los debates partidarios e internacionales; tales como el problema de la huelga general; la posición en torno al debate sobre el revisionismo y el reformismo; el debate acerca del "ministerialismo" (es decir, sobre la colaboración de los socialistas con fuerzas políticas ajenas al mundo obrero); el posicionamiento de los socialistas franceses en torno a la forma de gobierno republicana, entre otros.

Nos proponemos acercarnos a estos temas a través de un estudio de caso: la obra del periodista y militante socialista Paul Louis (1872-1948). El mismo comenzó su militancia en la corriente Blanquista del socialismo francés, en la organización CCR (Comité Révolutionnaire Central), que después pasó a llamarse PSR (Parti Socialiste Révolutionnaire). A su vez, colaboró con varias publicaciones socialistas y radicales, fundamentalmente . En estos trabajos, se conformó tempranamente como un especialista en política exterior, colonialismo e imperialismo. Con la fusión de las corrientes Blanquistas y Guesdista en el PSdeF (Parti Socialiste de France) pasó a esta organización, para finalmente confluir en la SFIO (Section française de l'Internationale ouvrière) en 1905, donde Louis representaría el área del Sena en el Gran París en los Congresos Socialistas nacionales y sería miembro del Consejo Nacional (Day y Gaido 2012: 129). A partir de allí, concentró su producción en una serie de libros que tenían por objetivo fijar posición sobre varios problemas de la teoría marxista y la práctica política de los socialistas, así como un balance sobre el aporte de varias de las corrientes e individuos del socialismo francés. A su vez, participó de varios debates partidarios y de la Internacional sobre estos temas ${ }^{1}$.

Nuestro primer problema de investigación es cuáles son las características específicas de los análisis del colonialismo/imperialismo ${ }^{2}$ producidos por Paul Louis: sus fundamentos económicos, su caracterización de los distintos países imperialistas, sus conclusiones políticas. Nuestro énfasis en este autor y el período "temprano" analizado parten de la

\footnotetext{
${ }^{1}$ Posteriormente al rango cubierto por este artículo, Paul Louis continuó su actividad política. En 1910 participó del Congreso Socialista de París y formó parte del Consejo Nacional de la SFIO. Durante la guerra, formó parte del CAP (Commission administrative permanente, órgano dirigente de la SFIO) y a partir de 1917, del Bureau del Partido (DBMOF 2007). Durante la guerra, probablemente por desilusión con la actitud de apoyo a la guerra de la mayoría de los socialistas alemanes apoyó inicialmente la unión sacré, un compromiso de la izquierda francesa de no oponerse al gobierno durante la guerra. No obstante, después de la revolución Rusa de 1917, viró de posición y apoyó a los bolcheviques; más tarde, defendió la afiliación con la Tercera internacional en el Congreso de Tours de la SFIO de 1920, deviniendo miembro del Partido Comunista Francés. En 1923 fue expulsado, participando después del PUP (Parti d'Unité Prolétarienne) que se reunificó con la SFIO en 1936. Cesó su actividad política durante la Segunda Guerra Mundial (Day y Gaido 2012: 130).

${ }^{2}$ Frente a esto, cabe una aclaración terminológica: el término más común en uso en Francia de 1880 en adelante era colonialismo; la palabra imperialismo tenía un uso general que significaba simplemente la presión por conquistas (Bédarida 1974: 26-28). Más tarde designó en un primer momento una política que buscaba englobar el conjunto de posesiones coloniales de un imperio, para pasar a usarse después como una etapa del capitalismo. En su obra, veremos todos estos usos y planteos, que irán modificándose en el tiempo.
} 
Manuel Quiroga, Teorías del imperialismo y marxismo en el socialismo francés temprano: el caso de Paul Louis (18961907) / Theories of imperialism and Marxism in the early French socialism: the case of Paul Louis (1896-1907), Revista Izquierdas, 27, abril 2016, ISSN 0718-5049, pp. 342-367

siguiente constatación: El análisis de los posicionamientos y la producción de los socialistas en torno al problema del imperialismo ha enfatizado generalmente el análisis de las "grandes teorías" articuladas, que surgieron en forma relativamente tardía, y donde destacan las obras de Luxemburg y Lenin (Luxemburg 1951 y Lenin 1970); o se ha limitado en lo fundamental a un análisis de los Congresos internacionales ${ }^{3}$.

En general, el énfasis en estas grandes teorías ha implicado soslayar gran número de publicaciones previas sobre el tema, que permiten analizar la construcción de las posiciones del socialismo internacional frente a estos problemas como un proceso donde intervinieron múltiples autores, en estrecha relación con la dinámica política de estas organizaciones. La publicación de Day y Gaido (2012) permitió impulsar un análisis de este tipo en la medida que se editaron numerosos escritos previos de socialistas de distintas partes de Europa, entre los cuales aparecen algunos escritos de Paul Louis. No obstante, el énfasis está en el análisis de los teóricos austríacos y alemanes, lo que, si bien es explicable por el predominio político de ambos partidos en la Segunda Internacional, y por la fuerte influencia de las publicaciones en lengua alemana sobre los análisis del colonialismo y el imperialismo, deja como laguna a investigar en más profundidad la producción de socialistas de otros países sobre estos temas. El mismo énfasis existe en el trabajo de Andreucci (1988).

Nuestro segundo problema de investigación refiere a cómo se articuló la relación entre "debates generales" del marxismo de la época con posicionamientos en torno al colonialismo/imperialismo. En relación a esto, los debates sobre el colonialismo y el imperialismo aparecieron con mayor fuerza en el socialismo internacional a partir del comienzo de la llamada controversia revisionista en el socialismo alemán, con importantes repercusiones internacionales. El mismo fue desatado por el socialista alemán Eduard Bernstein, quien defendió una revisión evolucionista y reformista del marxismo, planteando la necesidad del socialismo de concentrarse en reformas inmediatas, abandonando los objetivos "finales" revolucionarios fundándose en una serie de tendencias: la tendencia de la clase media a crecer, la negación de que la tendencia a la crisis era algo inherente al capitalismo, el rechazo de la dialéctica, de la dictadura del proletariado, de la teoría del colapso, etc. Estos argumentos y sus conclusiones fueron atacados por numerosos autores, entre los cuales destacaron Karl Kautsky y Rosa Luxemburg (ver los principales documentos del debate en Tudor y Tudor 1988).

La relación de estos debates era lógica, y estaba dada por lo siguiente: La actitud de los socialistas hacia la expansión colonial de sus propias naciones, no podía aparecer desconectada de la actitud de los socialistas hacia la colaboración con los partidos políticos burgueses y hacia su propio Estado. Si se pensaba que su propio Estado era reformable desde dentro a partir de la colaboración con las fuerzas políticas burguesas, y si se tenía una concepción básicamente positiva del desarrollo capitalista pensada en forma evolucionista (tal como podríamos caracterizar, en forma simplificada, las posiciones de Eduard Bernstein) el apoyo a la expansión colonial del propio país (en palabras de Bernstein, la elaboración de una "política colonial socialista") aparecía como una consecuencia lógica.

${ }^{3}$ Un ejemplo del primer enfoque en Brewer (1980), un ejemplo del Segundo en Joll (1976). 
Por el contrario, una actitud de oposición exigía un posicionamiento alternativo sobre estos problemas.

En el socialismo francés estos problemas aparecieron alrededor de debates de apariencia "táctica" pero donde se ponían en juego las posiciones fundamentales en torno al rol de los partidos socialistas frente al Estado y el resto de los partidos. En el período que analizamos en este artículo, esto se vio en el "Affaire Dreyffus", donde se puso en discusión la posición de los socialistas frente a la forma de gobierno republicana; en el debate del "ministerialismo"; en la caracterización de la Revolución Rusa de 1905; y en el debate sobre la huelga general, especialmente importante en Francia dada la influencia que este método de lucha y la propaganda en torno al mismo tenía en el sindicalismo francés (a la inversa que en Alemania).

A veces la relación entre estos temas generales de debate y el colonialismo/imperialismo es explícitamente producida por los propios autores o actores políticos; a veces, por la diversidad temática de los escritos, esta no es explícita, pero puede reconstruirse en forma tentativa ligando la producción con la trayectoria política del autor, las publicaciones y las organizaciones en que participó.

En esta investigación, partimos del presupuesto de que no es posible comprender la producción teórica de autores tan estrechamente ligados a la actividad política por fuera de la disputa de tendencias que atravesó a estas organizaciones. Por tanto, empezamos reconstruyendo la trayectoria de Paul Louis en el socialismo francés y la relación que mantuvo con sus distintas tendencias.

Nuestra hipótesis de trabajo, es que Paul Louis trató de superar un análisis estereotipado aportando algunos análisis de los fundamentos económicos del colonialismo y el imperialismo, tales como las disputas comerciales, el proteccionismo, la concentración de capitales y los trusts. No obstante, de conjunto tampoco Paul Louis pudo superar del todo las herencias republicanas y nacionales en sus primeros escritos, así como cierto mecanicismo en sus conclusiones. Más adelante, en un momento de radicalización política, desarrolló una concepción más rigurosa del imperialismo como fase. A partir de la unificación partidaria en 1905, trató de fundamentar una versión del marxismo con características originales que no permiten encuadrarlo simplemente dentro de alguna de las tradiciones previas del socialismo francés; la misma enfatizaba la necesidad de la acción política, la crítica al reformismo (cuyas raíces ubicaba en la actividad de los intelectuales y parlamentarios socialistas), la defensa de la huelga general como parte de su preocupación por conjugar los componentes sindical y político del movimiento obrero, y una concepción más ajustada de la posición que debían tener los socialistas ante la República.

\section{El socialismo francés y sus tendencias hasta 1896}

Un autor reciente compara de la siguiente forma el panorama de los comienzos del socialismo en Francia y Alemania: "Mientras que Alemania en este momento presentaba una imagen más bien simple de unidad socialista y crecimiento continuo, Francia muestra 
Manuel Quiroga, Teorías del imperialismo y marxismo en el socialismo francés temprano: el caso de Paul Louis (18961907) / Theories of imperialism and Marxism in the early French socialism: the case of Paul Louis (1896-1907), Revista Izquierdas, 27, abril 2016, ISSN 0718-5049, pp. 342-367

una imagen mucho más complicada, incluso confusa, de rupturas conflictos y coaliciones temporarias" (Steenson 1991: 129).

Hacia la década de 1890 las tendencias del socialismo francés incluirían a los Blanquistas los Guesdistas, los Posibilistas, los Allemanistas y un numeroso conjunto de diputados Independientes. Este panorama a veces hace difícil de entender los motivos que separaban a las distintas tendencias; el libro de Bernard Moss (1976), plantea una explicación útil. Su planteo es que dadas las características del desarrollo industrial de Francia, todavía incipiente a fines del siglo XIX y principios del Siglo XX, la mayor parte del movimiento socialista fue llevado adelante por obreros calificados de oficio, antes que por un proletariado industrial clásico. Esto llevará según el autor al predominio de una forma de "socialismo de oficio", donde se imaginaba que el sindicato local cumpliría las funciones de gobierno de la producción en un futuro socialista. Esto implicó un obstáculo para la penetración del marxismo en el movimiento socialista francés.

A pesar de la importancia de Francia en la actividad política y la obra de Marx y Engels, el marxismo conoció un desarrollo tardío en Francia en relación a otros países. Un indicio de esto es que las principales obras del marxismo, incluso las que lidiaban específicamente con Francia, fueron traducidas o editadas en el país muy tardíamente ${ }^{4}$. Tomó la forma de una corriente política particular nucleada alrededor de Jules Guesde. Guesde estaba influido por la "Ley de Hierro de los Salarios" de Lassalle, que planteaba la tendencia de los salarios a bajar al mínimo de subsistencia en condiciones de una economía industrial (Steenson 1991: 129).

La dificultad de mantener publicaciones estables y la poca cantidad de individuos con formación e inclinación hacia las actividades teóricas, hizo que los Guesdistas tuvieran en general escasos desarrollos originales del marxismo (Steenson 1991: 132). Su énfasis estaba puesto en la necesidad de la acción política y la organización en partido de la clase obrera. Las elecciones eran consideradas sobre todo como un instrumento de propaganda y reclutamiento (Cole 1975: 306).

El primer intento de formar una organización socialista en Francia vino de la fundación del Fédération des travailleurs socialistes de France en 1878, organización formada principalmente por miembros de sindicatos que vino a señalar la superación del cooperativismo por un planteo "colectivista" (es decir, de socialización de los medios de producción) donde los Guesdistas participaban como una tendencia minoritaria; Moss caracteriza la tendencia mayoritaria como un colectivismo pacífico (Moss 1976: 6). La primera ruptura del partido versará sobre la cuestión del federalismo versus centralismo al

\footnotetext{
4 "La Miseria de la Filosofía", si bien había sido editada en 1847, no atrajo casi atención en ese tiempo; fue reeditada recién en 1880 por el grupo del periódico Egalité. La primera edición francesa en Francia del "Manifiesto Comunista" fue editada por el mismo grupo en 1882. "La Guerra Civil en Francia" fue editada en Bélgica y alcanzó cierta difusión, pero la primera edición confirmada en Francia salió recién en 1900. "La Lucha de Clases en Francia" fue editada en francés recién en 1891, y "El Dieciocho de Brumario de Luis Bonaparte" en 1900. Sólo "El Capital" había conocido una temprana edición francesa, en 1872 (Steenson 1991: 111-113)
} 
Manuel Quiroga, Teorías del imperialismo y marxismo en el socialismo francés temprano: el caso de Paul Louis (18961907) / Theories of imperialism and Marxism in the early French socialism: the case of Paul Louis (1896-1907), Revista Izquierdas, 27, abril 2016, ISSN 0718-5049, pp. 342-367

interior de la organización partidaria, donde los Guesdistas se abrirían para formar el Parti Ouvrier, en 1882, más tarde renombrado en 1893 como POF, Parti Ouvrier Français (Moss 1976: 110). Esto puede parecer menor, pero implicaba una cuestión de fondo importante: Si los socialistas "de oficio" basaban su organización en el gremio profesional (al que consideraban base de organización de la sociedad futura), y desconfiaban tanto de la teoría como de los intelectuales socialistas, justificando la necesidad del federalismo por las desigualdades regionales y entre sectores de producción, los Guesdistas sacaban una conclusión opuesta de esas mismas desigualdades, buscando concentrar su esfuerzo en organizar al proletariado más moderno, fabril (Moss 1976:113), especialmente entre los trabajadores textiles del norte:

cuya condición de clase - bajos salarios, falta de calificación y debilidad organizativa - confirmaba su esquema Lassalleano. Careciendo de su propia tradición socialista, estos trabajadores requerían una teoría de clase y una organización introducidas desde afuera (Moss 1976: 120).

Si los Guesdistas enfatizaban el predominio del Partido, los Posibilistas se presentaban como agentes de los sindicatos, y abrían su organización a cualquier sindicato más allá de su afiliación y postura (Moss 1976: 125).

Otra corriente que existió en un primer momento al margen de estos esfuerzos de organización partidaria obrera fueron los Blanquistas, donde comenzó su militancia Paul Louis. Esta corriente combinaba hacia la década del 80 una figura aglutinadora (el legendario revolucionario Auguste Blanqui), una tradición de origen republicana radical que no había impedido una adhesión a las ideas "colectivistas" del socialismo de la época, con un énfasis más elitista en cuanto a la acción política, reflejada en la importancia que le otorgaban a los desclasados burgueses en el proceso revolucionario, con una actitud más favorable hacia la huelga general (Noland 1956: 10).

Estas corrientes tuvieron actitudes distintas durante el incidente de Boulanger. El ascenso de este político, que tendió a agrupar apoyos tanto de derecha como de izquierda alrededor de un confuso programa nacionalista y plebeyo, provocó una reacción de defensa republicana por parte de los Posibilistas, mientras que algunos Blanquistas le dieron un apoyo entusiasta (entre los cuales no estaba Paul Louis, que rechazaría el Boulangismo y confluiría con Vaillant en la nueva organización PSR $\neg$ Parti socialiste révolutionnaire $\neg$ fundada en 1898, ver DBMOF 2007). Los Guesdistas, por su parte, lanzaron la consigna "ni Ferry! ni Boulanger!", interpretando de alguna manera un contenido genuino tras el movimiento de agitación a favor de Boulanger (Moss 1976: 129).

Los Posibilistas usaron el incidente de Boulanger como justificativo para mantener alianzas electorales con los Radicales; sin embargo cuando los líderes del partido quisieron negociar una alianza permanente en 1890, provocaron una rebelión de la base del partido que purgó a los políticos más reformistas, organizando lo que se conoce como el Partido Allemanista, por el nombre de su líder, llamado oficialmente Parti ouvrier socialiste révolutionnaire (POSR). Esta organización enfatizaba la acción directa económica a través del sindicato 
Manuel Quiroga, Teorías del imperialismo y marxismo en el socialismo francés temprano: el caso de Paul Louis (18961907) / Theories of imperialism and Marxism in the early French socialism: the case of Paul Louis (1896-1907), Revista Izquierdas, 27, abril 2016, ISSN 0718-5049, pp. 342-367

como instrumento revolucionario del presente y órgano administrativo del futuro, colocando a la cuestión electoral en un segundo plano, y fundamentalmente como instrumento de propaganda (Moss 1976: 130).

Una relativa apertura política, sumada a un período de prosperidad económica, produjo en los 90 una tendencia a la deriva parlamentarista de casi todas las corrientes socialistas (Moss 1976: 135). Tanto los Guesdistas como los Blanquistas participaron de esta moderación. Algunos hitos fueron la colaboración con grupos de Radicales y Radicales Socialistas en las elecciones (en 1893, como parte de en un encuentro de republicanos de izquierda y socialistas, aceptaron un manifiesto que llamaba a los trabajadores a "salvar la República" votando candidatos "progresivos", ver Noland 1956: 31), que le permitirían aumentar su influencia electoral, y su apoyo al programa de Saint Mandé, que planteaba tres principios para la unidad de los socialistas: 1) La intervención del Estado para convertir de propiedad capitalista en propiedad nacional los medios de producción; 2) la conquista del gobierno por sufragio universal; 3) la creación de una "entente" obrera internacional (Noland 1956: 51). Como vemos, era un programa con escaso contenido revolucionario. A su vez, ambos grupos participaban de la Unión Socialista en el Parlamento (con predominio de diputados Independientes de orientación reformista), de la cual sólo los diputados Allemanistas se mantuvieron alejados (Moss 1976: 134). De instrumento de propaganda, la actividad electoral devenía crecientemente la actividad principal para los Blanquistas y Guesdistas (Noland 1956: 56-7).

La reacción al parlamentarismo se expresó en el crecimiento de un movimiento sindical crecientemente dominado por la idea de la huelga general y la reorganización de la sociedad bajo mando de los sindicatos, donde los Allemanistas pasarían a ser la fuerza dominante. La Primera organización sindical nacional fue la Federation des Syndicats et Groupes Corporatifs de France, conducida por una heterogénea coalición socialista. Si los Guesdistas durante el affaire de Boulanger habían aprobado resoluciones a a favor de la huelga general, poco después se volcaron en contra de la misma, denunciando la idea como utópica, particularmente en el Congreso de 1892. No obstante la idea siguió tomando cuerpo en dos nuevas organizaciones: una nueva central obrera la CGT, fundada en 1894, y la Federation National des Bourses de Travail, organizaciones que cumplían funciones de sindicato local, agencia de empleo obrera y mutual, fundada en 1896. Los Allemanistas serían los líderes más importantes de este movimiento sindical, y antecedentes directos del sindicalismo revolucionario; aunque otras corrientes socialistas (particularmente Blanquistas y anarquistas) tendrían mucho peso en el mismo también (Moss 1976: 138139).

\section{Socialismo Francés y Colonialismo}

En cuanto a las posiciones sobre el colonialismo francés, si bien no es posible hacer un estudio detallado del conjunto del socialismo francés, podemos dar algunos elementos que permiten situar la obra de Louis.

Bédarida (1974) identificó algunas posiciones ancladas en el socialismo francés, que califica de "debilidades congénitas" del conjunto de las corrientes que lo conformaban; derivadas de la herencia republicana o democrática radical de los socialistas franceses. En 
Manuel Quiroga, Teorías del imperialismo y marxismo en el socialismo francés temprano: el caso de Paul Louis (18961907) / Theories of imperialism and Marxism in the early French socialism: the case of Paul Louis (1896-1907), Revista Izquierdas, 27, abril 2016, ISSN 0718-5049, pp. 342-367

primer lugar, la persistencia de un "expansionismo de izquierda" asociado a la tradición de la Revolución Francesa, lo que brindaba bases ideológicas a algunas formas de colonialismo y resultaba reforzado por la tradición asimilacionista francesa en las colonias (Bédarida 1974: 28-29). En segundo lugar, lo que llama la debilidad teórica de las corrientes, que conducía casi siempre a la falta de análisis económicos profundos del fenómeno y a una concepción mayormente política del imperialismo, fundada en una "denunciación estereotípica de los crímenes de la colonización sin verdadero contenido económico" (Bédarida 1974: 29).

En el marco de esta tradición ideológica compartida, el autor distingue tres actitudes principales: la "rigorista", asociada a la condena clara de la colonización, la que llama "laxista", asociada a la admisión de una colonización pacífica y depurada de sus vicios, y la "dualista", representada sobre todo por las posiciones de Jean Jaurès que representaba una convivencia de las dos posturas, centrada en evitar la guerra en Europa (Bédarida 1974: 29). Estas posiciones tendían a entremezclarse en ocasiones entre las tendencias.

Los Guesdistas en los años 90 y 1900 adoptarían (salvo alguna excepción) una posición rigorista frente al colonialismo; un ejemplo clásico es la resolución sobre el tema del Congreso de 1895 del POF en Romilly:

Considerando que la política colonial es una de las peores formas de explotación capitalista, que tiene exclusivamente a agrandar el campo de ganancias de la clase propietaria a expensas de la sangre y el dinero del proletariado productor; considerando que sus expediciones llevadas a cabo bajo el pretexto de la civilización y el honor nacional llevan a la corrupción y destrucción de las poblaciones primitivas y desencadenan en la propia nación colonizadora todo tipo de azotes; considerando que la única forma realmente humana de asegurar salidas para la producción mecánica moderna es abolir las diferencias de clase y asegurar a los productores, maestros de las formas sociales de los medios de producción, el consumir ellos mismos la riqueza producida por su trabajo manual e intelectual; el decimotercer Congreso Nacional del POF protesta con todas sus fuerzas contra las expediciones coloniales filibusteras para las cuales ningún socialista consciente votará jamás ni un hombre ni una moneda (POF 1897: 47-8).

Esta será la base de las posiciones de Louis; pero partiendo de la misma, planteará posiciones más profundas. Mucho tiempo después, la descomposición de la tendencia Allemanista (cuyos miembros "políticos" se unirían al partido de Jaurès y perderían gran parte de su fuerza a partir de 1900, sobreviviendo muchos de sus ex militantes en el sindicalismo revolucionario de la CGT, ver Moss 1976: 134) generaría lo que Rebérioux llama las dos tendencias "hostiles al Estado" en la SFIO (Rebérioux 1968), representadas en publicaciones por las revistas La Guerre Sociale de Gustave Hervé, y Le Mouvement Socialiste dirigida por Hubert Lagardelle (que adoptaría estas posiciones hostiles al Estado y filo-sindicalistas recién a partir de 1904). En cuanto al problema colonial, La Guerre Sociale se caracterizaría por una posición de condena a las expediciones coloniales, de apoyo a las resistencias indígenas (especialmente de las colonias árabes) (Rebérioux 1964: 92-7), sin análisis demasiado profundos sobre las raíces del colonialismo y sus causas económicas (Rebérioux 1964: 98); en cuanto a Le Mouvement Socialiste, desde su giro filo 
Manuel Quiroga, Teorías del imperialismo y marxismo en el socialismo francés temprano: el caso de Paul Louis (18961907) / Theories of imperialism and Marxism in the early French socialism: the case of Paul Louis (1896-1907), Revista Izquierdas, 27, abril 2016, ISSN 0718-5049, pp. 342-367

sindicalista, prestará escasa atención al problema colonial, dada su estrecha concepción de los problemas específicos de la clase obrera (Rebérioux 1964: 101-2).

La posición de los laxistas, entroncando por ejemplo con los revisionistas alemanes, se planteaba como una posición realista que exigía una posición "positiva" frente a las colonias, especialmente en aquellas donde se había dado una temprana política asimilacionistas. Dos ejemplos de esta posición son las de los militantes Marie-Samuel Joseph Lagrosillière ("antillano de formación Guesdista") y René Arot. En estas posiciones la denuncia de los crímenes de la administración colonial se hacía con la perspectiva de que los colonizados debían luchar por la mejora de su situación en el marco francés, rechazando el separatismo y profundizando una postura asimilacionista hacia los colonizados. Variantes de estas posiciones seguirían apareciendo a lo largo de la historia de la SFIO; por fuera del marco temporal que trata este artículo existe un ejemplo notable: en 1912 la SFIO debatió un proyecto de "colonización socialista" consistente en el traslado de trabajadores franceses a Marruecos con el apoyo de nada menos que Guesde; el mismo sería rechazado por la oposición de Vaillant (de origen Blanquista) y Jaurès (Bédarida 1974: 31-32). Esto es testimonio de la escasa firmeza incluso de una tendencia tradicionalmente "rigorista" como la de Guesde en la medida que no se sustentaba en un análisis económico firme.

En cuanto a la posición "dualista" de Jaurès, se acerca bastante en sus primeros años al "laxismo" defendiendo los derechos de los nativos junto a la "penetración pacífica" de los intereses europeos a través de una entente cordial con los nativos. La diferencia es que pondrá quizás más énfasis en el derecho de los mismos a conservar parte de su propia cultura (Bédarida 1974: 3); en el caso de Argelia, por ejemplo, defenderá a los musulmanes en numerosas ocasiones ante los atropellos de los colonos y autoridades, pero sin salirse de una política de asimilación gradual (Ageron 1963: 29). El instinto práctico de Jaurès, centrado en evitar la guerra, lo llevará a examinar con atención las pretensiones coloniales de Francia, sobre todo después de 1905; tenderá a plantear que cada socialista debía luchar contra las pretensiones "excesivas" de su propio país para luchar contra la guerra, y reprocha que los doctrinarios por hostilidad teórica no examinen en detalle el problema colonial. Así su énfasis estará en evitar la guerra en Europa más que en la condena al hecho colonial en sí (Thomas 1960: 234).

En torno a este punto, nuestra hipótesis es que Louis se mantuvo en el marco de una posición rigorista (exceptuando alguna ambigüedad menor en alguno de sus escritos); buscando justificar la misma desde un análisis económico que superaba la posición más estereotipada que había sido típica del Guesdismo temprano.

\section{Análisis sobre el colonialismo: el problema de la herencia republicana} 1896-1899

Hacia fines de la década del 90 existía una tendencia hacia la unidad de las tendencias socialistas en Francia, basada en la moderación de las tendencias de izquierda. Si la explosión del asunto Dreyffus inicialmente generó diferencias entre quienes creían necesario defender al oficial judío (Allemanistas, Independientes y Posibilistas) y quienes lo veían como un enfrentamiento interburgués (Blanquistas y Guesdistas) finalmente todas 
Manuel Quiroga, Teorías del imperialismo y marxismo en el socialismo francés temprano: el caso de Paul Louis (18961907) / Theories of imperialism and Marxism in the early French socialism: the case of Paul Louis (1896-1907), Revista Izquierdas, 27, abril 2016, ISSN 0718-5049, pp. 342-367

las fracciones actuaron en conjunto frente a las amenazas a la República provenientes de la agitación de sectores monárquicos y derechistas (Noland 1956: 61-85). Un indicio de este clima de unidad era la popularidad de Benoît Malon, referente de una propuesta autodenominada "socialismo integral", que planteaba una "síntesis" entre los planteos revolucionarios y reformistas (Cole 1975: 311). Louis escribirá en sus primeros años en la revista de este último, La Revue Socialiste.

Desde sus primeros escritos sobre el colonialismo francés, Louis planteará con claridad la idea de que el colonialismo tiene un origen eminentemente económico, el de una búsqueda de mercados (débouchés) para las mercancías de los países industriales (Louis 1897a: 2425). Esta idea básica, se mantendrá en sus escritos posteriores, aunque analizada con más determinaciones económicas.

No obstante, planteará diferencias entre distintos tipos de colonización, enfatizando que, si algunas tienen causas más directamente mercantiles, otras devienen más de la presión militar: "La colonización inglesa es sobre todo mercantil; la nuestra es a la vez mercantil y militarista" (Louis 1897a: 25). A partir de esto desglosa tres principios que "comandan la colonización capitalista: "la sobreproducción industrial - el militarismo - la preocupación por las distracciones políticas" (Louis 1897a: 36). En cuanto al militarismo, los "oficiales que perpetúan en el seno de las naciones contemporáneas el espíritu feudal de la casta militar de antaño son (...) los promotores más activos del empuje colonial" (Louis 1897a: 37).

A su vez, tendrá un análisis particular del proteccionismo: si bien, coincidiendo con la mayor parte de los socialistas de su época, había criticado el proteccionismo para Francia por subir el costo de vida para la clase obrera (Louis 1896), planteará en esta etapa que el mismo "armoniza mal con el colonialismo" dado que:

Por una parte, Francia no recobra en sus posesiones la remuneración por sus gastos; por otra, ella debe temer, para un futuro más o menos cercano, su concurrencia sobre su propio mercado (...) El proteccionismo y la expansión colonial (...) quieren salvaguardar los mismos intereses de clase; mas teóricamente se anulan el uno al otro (Louis 1897b: 166).

Uno de los primeros hechos significativos vinculados con el imperialismo fue la guerra hispano-estadounidense (1898). El análisis del mismo reflejará la influencia de la tradición republicana sobre Louis. Si bien reconocerá la influencia de los intereses de los trusts industriales de EUU en la guerra con España, planteando que el gobierno norteamericano "cedía a la fatalidad del sistema capitalista" remataba diciendo que "sirviendo intereses egoístas, desembocarán en liberar una población justamente insurrecta" (Louis 1898a: 609610). A su vez, planteará que la simpatía prevaleciente con España en Europa se debía al monarquismo de las grandes potencias, y la subordinación de Francia a Rusia (Louis 1898a: 611). 
Manuel Quiroga, Teorías del imperialismo y marxismo en el socialismo francés temprano: el caso de Paul Louis (18961907) / Theories of imperialism and Marxism in the early French socialism: the case of Paul Louis (1896-1907), Revista Izquierdas, 27, abril 2016, ISSN 0718-5049, pp. 342-367

A su vez, en esta etapa expresará una fuerte confianza en los acuerdos diplomáticos como medio de alejar el peligro de guerra. Por ejemplo, en ocasión de una propuesta de desarme parcial lanzada por el zar de Rusia, planteará: “¿Quién no se regocijará, entre nosotros [socialistas], de ver a uno de los soberanos más poderosos secundar los esfuerzos que el proletariado universal multiplica sin tregua para asegurar la fraternidad entre los hombres?" (Louis 1898c: 258)

En ocasión de un acuerdo entre los gobiernos de Francia e Italia, expresará similar entusiasmo, planteando que "todo progreso de la propaganda pacífica es una victoria para nuestras doctrinas" (Louis 1899a: 35) llamando al acuerdo incluso "un signo y un símbolo de la fuerza proletaria. Es la democracia la que (...) ha querido, exigido, asegurado el reacercamiento" (Louis 1899a: 39). A su vez, expresaba la confianza de que significara un golpe al proteccionismo más prohibitivo (Louis 1899a: 37) y con que fuera un golpe mortal a la Triple Alianza (Alemania, Austria-Hungría e Italia), "aquella moderna Santa Alianza que hacía pesar sobre la democracia europea perpetuas amenazas de conflagración" (Louis 1899a: 40).

En un artículo sobre "una nueva fase de las relaciones internacionales" plantearía que "las sociedades civilizadas se encaminan hacia las coaliciones comerciales que serán el embrión de las federaciones del porvenir"; planteando un análisis contradictorio, que por un lado consideraba que preparaban "el triunfo del penúltimo estadio de la humanidad" antes del socialismo (otorgándole así cierta progresividad económica), matizado por la idea de que esta progresividad venía de facilitar la revolución: "Las luchas económicas, la concurrencia, los antagonismos se agravarán sin cesar, los conflictos sociales que son su consecuencia inmediata, se acentuarán (...) y precipitarán la revolución general que liberará al proletariado" (Louis 1898d: 395).

Junto a las ilusiones sobre EEUU, manifestaba ilusiones sobre el rol internacional de Gran Bretaña, que planteará como mayormente "pacífica" destacando sólo que "el partido imperialista" se orienta hacia la guerra (Louis 1898d: 399).

\section{Primeros escritos sobre el imperialismo: La política de federación aduanera: $1899-1900$}

El primer estudio serio de Paul Louis sobre el imperialismo fue publicado en 1899, refiriéndose al imperialismo "anglo sajón", en el sentido de proyecto de federación aduanera. Su apreciación acerca de que esta constituía un paso hacia la realización del ideal internacionalista es repetida; pero se enfatizaba mucho más sus peligros:

El imperialismo anglosajón ha devenido últimamente uno de los factores esenciales en la política mundial. Ha contribuido a oscurecer el horizonte de Europa mucho más que cualquier otro elemento. Su influencia en los eventos cotidianos es creciente y obvia (...) y debe ser considerado un principio de reorganización para la humanidad civilizada como un todo (Louis 1899b: 131). 
Manuel Quiroga, Teorías del imperialismo y marxismo en el socialismo francés temprano: el caso de Paul Louis (18961907) / Theories of imperialism and Marxism in the early French socialism: the case of Paul Louis (1896-1907), Revista Izquierdas, 27, abril 2016, ISSN 0718-5049, pp. 342-367

Consideraba que el imperialismo constituía un programa económico definido para la burguesía (Louis 1899b: 132) y, a diferencia de sus escritos de la primera etapa, subrayaba que el imperialismo británico no era el programa de ningún partido en particular, sino que "penetra (...) en todos los partidos (...) representados en el Parlamento británico" (Louis 1899b: 138); el mismo devenía de "la decadencia del comercio exterior británico, el estancamiento de la industria británica y la aprehensión que esta caída inesperada causó en la clase dominante" (Louis 1899b: 141).

$\mathrm{Si}$ bien planteaba contradicciones para llegar a la unión aduanera (especialmente la necesidad en algunos de los espacios coloniales de reducir las tarifas a los productos británicos) terminaba planteando: "La Federación anglosajona es más que una posibilidad futura porque está en el orden lógico de las cosas (...) su triunfo es sólo una cuestión de tiempo" (Louis 1899b:145).

Louis examinó también en esta etapa la actitud de los socialistas frente al problema colonial, preguntándose si debían tener una posición general, o si esta debería "diversificarse según el país, inspirándose en consideraciones particulares y razones transitorias" (Louis 1899c: 553). Su propia postura es que debía haber una doctrina general para el socialismo sobre el tema. Esto se dificultaba porque los gobiernos disfrazaban sus propósitos expansionistas bajo votos sobre cuestiones parciales en el Parlamento, y eso producía divergencias "lamentables" a la hora de votar entre los parlamentarios socialistas. A su vez lamentaba cómo no se le había dado la suficiente importancia al colonialismo en los congresos donde habían sido incluidos debates sobre el problema, aunque consideraba al error reparable (Louis 1899c: 554).

$\mathrm{Su}$ argumentación es que el colonialismo era un fenómeno universal, estrechamente ligado a las condiciones económicas de la época (Louis 1899c: 556); complejizando a su vez sus fundamentos económicos para la burguesía:

Atenuando, suprimiendo mismo por un tiempo los males de la sobreproducción, limita las crisis industriales y acelera su propio enriquecimiento; por otra parte, multiplicando sus ventas, puede ligeramente acrecentar, a título provisorio y (sic), por lo menos, mantener los salarios (Louis 1899c: 560).

Los beneficiarios del colonialismo correspondían a un "pequeño grupo" en el seno "del Estado mayor de la clase dirigente"; el grupo de "financieros sin escrúpulos, de lanzadores de títulos, de especuladores" (Louis 1899c: 571). Este planteo de asignarle el mayor interés en la expansión colonial a la parte financiera del capital se haría un planteo común en la época: Kautsky plantearía la contraposición entre la política proteccionista e imperialista del capital monetario con la política supuestamente librecambista y pacifista del capital industrial en un artículo del año siguiente (Kautsky 1900).

A su vez señalará que más allá de que el movimiento colonizador, sirve a los intereses de la clase dominante, por gravar los presupuestos y acentuar las amenazas de bancarrota demostraría su decadencia intelectual y política (Louis 1899c: 570); visible también en la difusión del racismo, sobre el cual planteaba "es una de las taras más graves de nuestra 
Manuel Quiroga, Teorías del imperialismo y marxismo en el socialismo francés temprano: el caso de Paul Louis (18961907) / Theories of imperialism and Marxism in the early French socialism: the case of Paul Louis (1896-1907), Revista Izquierdas, 27, abril 2016, ISSN 0718-5049, pp. 342-367

época que una doctrina tal haya podido solamente ser formulada, y que se la haya pretendido justificar con consideraciones de apariencia científica” (Louis 1899c: 563).

Su conclusión planteará:

Lucharemos sin tregua contra la colonización porque viene de la esencia misma del régimen capitalista (...) resultante de la infraestructura misma del régimen económico y social contemporáneo, la expansión colonial persistirá mientras dure éste (...) nos basta de asistir impasibles, listos para recoger los efectos (...) La historia trabaja por nosotros. ¡Saludemos su obra ineluctable y continua! (Louis 1899c: 572).

En esta etapa manifestaría también un mayor escepticismo hacia la posibilidad de los tratados diplomáticos para reducir los armamentos. Sobre la misma iniciativa de desarme del zar que lo había entusiasmado en la etapa anterior, planteaba ahora que era "poco probable que se llegara a un resultado concreto" (Louis 1899d: 660) y que tanto el Congreso de los Social Demócratas belgas como la conferencia internacional de Bruselas del 28 de mayo habían llegado a la misma conclusión: sólo "la organización popular y la revolución social pueden asegurar la ruina del régimen de armamentos" (Louis 1899d: 662). Enmarcaba esto en una reflexión marxista sobre el ejército: "institución estrechamente ligada al régimen capitalista, sea que el mismo tome la forma realista, clerical o la forma jacobina-burguesa" (Louis 1899d: 658-659).

En referencia a su análisis del carácter de los EEUU, también se operará un desplazamiento. Si bien manifestará cierta admiración por su enorme desarrollo económico, y destacará como era inicialmente una república pacífica, planteará que el conflicto hispano-americano, derivado de "la fatalidad económica" implicará necesariamente más conflictos (Louis 1899f: 181-182). Planteaba que esto se relaciona con el desarrollo de los trusts:

Aquí se ha manifestado en pleno florecimiento el trust, el gran sindicato patronal que engloba (...) toda una industria, incluso varias industrias conexas (...) ¿no son los mismos la expresión misma de la burguesía del dinero constituida en clase? (Louis 1899f: 182-183)

Aseguraba que el trust estaba destinado a triunfar y que su éxito constituía un golpe contundente a los doctrinarios del librecambio (Louis 1899f: 198-199).

Comentando el conflicto sudafricano de 1899, que sería junto con el hispano americano de 1898, uno de los que produciría gran número de reflexiones sobre el tema del imperialismo, lo presentaría como una prueba de fuerza para el imperialismo británico por subordinar a los Boers (Louis 1899e: 61), manifestando, como la mayor parte de los socialistas, simpatías por estos últimos (los cuales combatían "por la emancipación de una nacionalidad", Louis 1899h: 541). A su vez, señalaba la hipocresía en la serie de protestas contra la conducta británica en varias naciones, planteando por primera vez que existía también un imperialismo francés, japonés, americano e italiano, todos formando parte de los conflictos internacionales motivados por disputas comerciales (Louis 1899h: 543). A su vez, planteaba en un artículo la entrada de Alemania al movimiento colonial, y preguntándose si la Social Democracia alemana negaría los créditos para la expansión 
Manuel Quiroga, Teorías del imperialismo y marxismo en el socialismo francés temprano: el caso de Paul Louis (18961907) / Theories of imperialism and Marxism in the early French socialism: the case of Paul Louis (1896-1907), Revista Izquierdas, 27, abril 2016, ISSN 0718-5049, pp. 342-367

colonial, o se asociaría a la misma "según la fórmula oportunista desarrollada por Bernstein", daba su propia respuesta: era "deber estricto" de "todas las fracciones socialistas" rechazar los créditos militares (Louis 1900a: 99-100).

En la víspera del Congreso Internacional de París del 1900, Louis abordaría la cuestión china. Comentaba las diferencias entre los socialistas sobre el tema, en particular que Bernstein se había mostrado totalmente favorable a la expansión de Alemania, y que Kautsky se había opuesto a dicha postura. Reseñaba como, incluso sin simpatías por el régimen capitalista, algunos socialistas podía argumentar: a) que al difundir el industrialismo, el colonialismo intensificaba la concurrencia y por tanto acercaba el "cataclismo final" del capitalismo; b) que el colonialismo es parte inseparable del capitalismo y por tanto no se puede detener su expansión y c) que dicha expansión costosa y bárbara es la última carta de la burguesía, que no puede sostenerse más que a golpes de cañón para procurarse "mercados" [para sus mercancías]. (Louis 1900b: 197-198). Exhortaba a lograr una posición unitaria de los socialistas más allá de cualquier hecho puntual, a pesar de que admitía la complejidad del tema debido a las masacres de europeos cometidas por los Bóxers (Louis 1900b: 200-201). El Congreso de París, con una intervención dominante de Rosa Luxemburg, terminaría aprobando una resolución condenando en bloque el colonialismo, el imperialismo y el militarismo (Day y Gaido 2012: 21-22).

En los argumentos a y b, vemos como un análisis planteado como marxista, podía derivar, por su propio mecanicismo, en conclusiones que planteaban cierto carácter "progresivo" del colonialismo; Louis no se termina de despegar en esta etapa de estos análisis; su mayor desliz a este respecto se dará en un artículo llamado "La evolución económica del globo". En este, analizaría una serie de transformaciones económicas en el mundo, entre las cuales listará la concentración de capitales como una consecuencia del industrialismo, que se extendía también a la esfera agrícola, y a la cual no cabía oponerse. Llegaba a advertir un principio de la ley de desarrollo desigual y combinado, al advertir que los países más recientemente llegados a la concurrencia son los que presentan "los equipamientos más sintéticos y las concentraciones obreras más fuertemente disciplinadas", lo que sería el caso de Japón, Rusia, Argentina, las colonias británicas autónomas y el Transvaal (Louis 1900c: 707 y 709). Volvería a plantear la conexión estrecha entre industrialismo, militarismo y capitalismo, en lo que calificaría de "guerra económica", planteada por las luchas comerciales, que escondían en su seno el conflicto de clases (Louis 1900c: 709). No obstante, al analizar el imperialismo, planteará que es un "principio de orden" y que: "a pesar de las taras que conlleva, a pesar del orgullo nacionalista y el espíritu de agresión que guarda en sí, merece ser acogido como una expresión de progreso internacional" (Louis 1900c: 710). Esta formulación desafortunada, que contradecía en parte su análisis anterior sobre el imperialismo anglo sajón y el carácter caótico de la guerra económica, se justificaba en que esto aumentaba el ejército industrial de reserva, creando condiciones para la revolución (Louis 1900c: 712).

En otro artículo, plantearía no obstante sobre el carácter de clase del imperialismo, que "a ambos lados del Atlántico" es claramente la burguesía quien lo impulsa, planteando que en Francia "la aristocracia agraria, clerical, realista y bonapartista luchó por más de diez años 
Manuel Quiroga, Teorías del imperialismo y marxismo en el socialismo francés temprano: el caso de Paul Louis (18961907) / Theories of imperialism and Marxism in the early French socialism: the case of Paul Louis (1896-1907), Revista Izquierdas, 27, abril 2016, ISSN 0718-5049, pp. 342-367

contra las anexiones coloniales antes de capitular" (Louis 1900d: 150.) Destacará cómo la burguesía británica determina las relaciones exteriores del país a través de sus sociedades por acciones y sus sindicatos financieros, lo que sucede igualmente en EEUU a través de los trusts (Louis 1900d: 151-152). Esto implicará la eliminación de cualquier resabio de la idea de que son los sectores económicos atrasados o una minoría financiera los que impulsan el imperialismo, superando sus propias concepciones anteriores.

La colaboración de Louis con Revue Socialiste terminaría este año, en el mismo momento donde el clima unitario de las tendencias del socialismo francés tendía a descomponerse. El asunto del "ministerialismo" implicó la división en dos fracciones del socialismo francés, entre quienes aceptaban o defendían la entrada a un gobierno de coalición con republicanos burgueses del socialista Millerand, y quienes se opusieron. En este último grupo estaban los Guesdistas y Blanquistas, junto a un grupo más pequeño llamado Alianza Comunista que librarían una batalla contra el Ministerialismo en tres Congresos planteados para unificar a los grupos socialistas, en los años 1899, 1900 y 1901. Su oposición a esta política llevó a un proceso de radicalización de estos grupos, mientras sus adversarios les recordaban su propia política anterior de alianza con los Radicales y Radical-Socialistas durante gran parte de la década de 1890. La fracción Ministerialista estaba formada por los Independientes, Posibilistas y parte de lo que quedaba de los Allemanistas. A su vez, distaba de ser homogénea hacia adentro, con fracciones más de izquierda que veían la participación en un gobierno de defensa republicano como una medida táctica justificada sólo temporalmente por el clima de inestabilidad fogoneado por la derecha, mientras que otros eran más favorables a la táctica en forma sostenida. El principal portavoz de esta fracción fue Jean Jaurès. El predominio numérico de estas fracciones hizo que los Guesdistas se retiraran después del Congreso de París del 1900, rechazando por el momento la posibilidad de la unificación socialista. Los Blanquistas permanecerían un Congreso más, para finalmente retirarse en 1901, después del Congreso de Lyon (Noland 1956: 115-137).

\section{Radicalización política y los inicios de una teoría del imperialismo como fase del capitalismo $1901-1904$}

En esta etapa Louis pasaría a publicar en publicaciones más generales, no socialistas, donde paradójicamente pareciera haber tenido más oportunidad para desarrollar sus análisis económicos.

En esta etapa se realizará un análisis más ajustado de los sus fundamentos económicos del colonialismo/imperialismo, entre estos, un análisis más ajustado de la sobreproducción:

La sobreproducción deviene (...) el mal crónico del mundo moderno. Ante la creciente concurrencia, el industrial se encuentra obligado a bajar rápidamente sus precios. Mas, para reducir sus tarifas, se ve obligado a lanzar más [productos] al consumo, para recapturar a través de la cantidad todo lo que ya no gana en tal o cual entrega en particular. Y para acrecentar su contingente de fabricación, desarrolla su equipamiento que representa un capital inmovilizado a amortizar. Todo viene de la sobreproducción y todo conduce allí (Louis 1901a:163) 
Manuel Quiroga, Teorías del imperialismo y marxismo en el socialismo francés temprano: el caso de Paul Louis (18961907) / Theories of imperialism and Marxism in the early French socialism: the case of Paul Louis (1896-1907), Revista Izquierdas, 27, abril 2016, ISSN 0718-5049, pp. 342-367

Plantea que la colonización no arroja las ventajas económicas que los europeos esperan, porque o bien los intercambios coloniales tienen un rol mediocre en el conjunto del comercio, o porque "las anexiones exóticas, después de haberse abierto ampliamente a los productos metropolitanos, estrechan sus demandas y reducen sus cuotas" (Louis 1901a: 169).

En 1902 se formaría el Parti Socialiste de France, al que pertenecería Paul Louis, por unión de los principales grupos antiministerialistas: El POF (Guesdista), el PSR (Blanquista), y la Alianza Comunista. Los Guesdistas serán la absoluta mayoría del nuevo partido, aportando cinco sextos de sus miembros (Willard 1965: 546). Sobre los problemas relacionados del patriotismo, internacionalismo y el colonialismo, el partido tendrá dificultades para sintetizar posiciones de forma coherente; así, el PSdeF "contribuye a nutrir a la vez una cierta forma de nacionalismo y la tendencia herveísta" (Willard 1965: 557). En torno a las guerras y conquistas coloniales, predominará una visión algo esquemática de analizarlas como "producto necesario (...) del sistema capitalista". Por influencia sobre todo de los Blanquistas, que tendían a enfatizar este punto, la lucha antimilitarista retomará importancia en la propaganda del nuevo partido. No obstante, carecerá en general de medidas prácticas que acompañen estas declaraciones, exceptuando el lanzamiento, algunos años más adelante, de un movimiento de agitación contra la guerra ruso-japonesa (Willard 1965: 558).

Este clima, y algunas producciones tanto francesas como internacionales del momento (que analizamos más abajo), influyeron en que Louis abordara el problema de los trusts. En una explicación más completa de los fundamentos económicos del imperialismo británico, planteaba cómo los hombres de Estado del país tendían a atribuir la depresión económica del país a los cárteles y trusts, lo cual era quizás exagerado, mas era sin dudas uno de sus fundamentos más serios (Louis 1903a: 661)

Vinculaba el funcionamiento de los trusts con un intento de superar la sobreproducción:

Los cárteles venden al exterior a cursos muy inferiores incluso al precio de coste (...) Ora se trata de conquistar un mercado que se niega (...) ora los directores de la asociación se preocupan de expulsar al exterior su exceso de mercancías, a fin de evitar la sobreproducción y por tanto la depreciación interior (Louis 1903a: 662).

Destacaba cómo los cárteles resultan del proteccionismo y cómo no existen en Inglaterra por su adhesión hasta ahora dogmática al librecambio, lo que la ponía en desventaja con respecto a sus nuevos competidores (Louis 1903a: 662-663).

Es interesante que este trabajo se publica en el mismo año que un trabajo de Rudolf Hilferding, titulado "El Cambio de función de los aranceles proteccionistas: Una tendencia de la política comercial moderna" donde desarrollaba con mayor profundidad teórica este problema, en referencia al desarrollo histórico de la política exterior alemana (Hilferding 1903). No podemos comprobar si Louis conocía el artículo, pero el argumento ciertamente es similar. A su vez, en el mismo año se había publicado un libro escrito por un compañero de partido de Louis, de origen Guesdista, Paul Lafargue, Les trusts americains, donde analizaba la creciente influencia de los trusts, su tendencia a producir una "superabundancia 
Manuel Quiroga, Teorías del imperialismo y marxismo en el socialismo francés temprano: el caso de Paul Louis (18961907) / Theories of imperialism and Marxism in the early French socialism: the case of Paul Louis (1896-1907), Revista Izquierdas, 27, abril 2016, ISSN 0718-5049, pp. 342-367

de medios de producción" y su presión para avanzar en la política imperialista (Willard 1965: 552-3). Esta obra original puede verse como un interesante desarrollo del marxismo francés de gran importancia y calidad, paralelo a discusiones similares en Alemania: sin dudas influyó en Louis.

En su artículo de 1904 en el diario Mercure de France, es donde aparecerá claramente la idea del imperialismo como fase: "El mundo atraviesa, a la hora presente, la era del imperialismo (...) el imperialismo y el socialismo constituyen la oposición fundamental del momento" (Louis 1904: 100).

Destaca que el imperialismo implica para la burguesía el "esfuerzo supremo por conservar su riqueza, su dominación política, su autoridad social. Dicho esfuerzo conlleva la conquista territorial (...) el cierre de mercados, la creación de un imperio cerrado". Los antiguos apetitos militares, dinásticos y nacionales son usados por el imperialismo sin ningún poder propio: los usa mientras le sirven y si no, les impone silencio (Louis 1904: 101).

Dada la permanencia de la sobreproducción y las crisis, es necesario buscar nuevas clientelas: o se monopoliza el mercado interno mediante leyes (el proteccionismo) o se buscan anexiones afuera. Por tanto: "El imperialismo coordina el colonialismo y el proteccionismo" (Louis 1904: 105).

Concluía:

el imperialismo contiene en sí mismo su remedio. Si debe engendrar la guerra, todo prueba que los conflictos armados del futuro, inmediata o progresivamente, producirán golpes irreparables a las instituciones sociales de los estados que habrán participado de los mismos (Louis 1904: 112-113).

En este pronóstico, sus ideas anteriores sobre la posibilidad de que el imperialismo llevara a la revolución proletaria tomaban un carácter más concreto. Este artículo sería leído por Lenin, quien incluiría un resumen del mismo en sus Cuadernos sobre el imperialismo, destacando aquellas partes que llevan a interpretar al imperialismo como fase (Lenin 1964).

El mismo se elaboró en un año de fuerte radicalización para el PSdeF: En su discurso en el Congreso Internacional de Amsterdam, en medio de una polémica feroz entre defensores y detractores del la participación ministerialista, Guesde plantearía que la lucha contra el ministerialismo estaba ligada a lograr una posición consecuente de lucha contra la expansión colonial, señalando las vacilaciones de sus adversarios en este punto (Noland 1956: 170-1). La resolución de Amsterdam significaría un duro revés para los ministerialistas, y se llamaría a la unificación partidaria sobre la base del rechazo a la colaboración permanente en los gobiernos burgueses (Noland 1956: 165-184). A su vez, en relación al imperialismo, los desarrollos teóricos más importantes de Paul Louis y Lafargue no provocarían cambios significativos ni en el tono ni en el contenido de las declaraciones del partido: El Congreso de Lille del PSdeF, previo al Congreso de Amsterdam, adoptó una declaración casi calcada de la vieja declaración de Romilly de 1895 que hemos mencionado más arriba (Willard 1965: 558). 
Manuel Quiroga, Teorías del imperialismo y marxismo en el socialismo francés temprano: el caso de Paul Louis (18961907) / Theories of imperialism and Marxism in the early French socialism: the case of Paul Louis (1896-1907), Revista Izquierdas, 27, abril 2016, ISSN 0718-5049, pp. 342-367

\section{Debates sobre reformismo, ministerialismo, huelga general y forma de gobierno republicana}

Louis publicará un importante libro en 1905, L'Avenir du socialisme, donde encarará varios de los debates más importantes del socialismo de su época. Comenzará reseñando los debates causados por el revisionismo, que consideraba ponían en cuestión muchas de las tesis de base del socialismo:

Es así que la concentración progresiva de capitales ha sido impugnada, que la proletarización creciente de las naciones de base capitalista ha sido formalmente negada, y que el antagonismo de clases ha devenido, bajo la pluma de algunos críticos, pura logomaquia (Louis 1905a: 3)

Con esto se refería sin dudas a las posiciones de Bernstein. Planteaba que los revisionistas no habían tenido éxito en "imponer sus conclusiones a la masa del socialismo" (Louis 1905a: 3). Sobre el problema de la pauperización/ proletarización planteaba que no se debían confundir ambos conceptos: los salarios podían subir en un momento determinado al mismo tiempo que cada vez más sectores de las clases medias se proletarizaban, agudizando la contradicción de clases (Louis 1905a: 4). Dedicará numerosas páginas a analizar la suerte del socialismo en distintos países, entre los cuales sobresale su descripción de la revolución rusa en curso:

La impotencia de los detentores de la fortuna mobiliaria, que en otras partes han conducido e inspirado las revoluciones, ha realzado tanto más el rol del socialismo proletario. De las masas obreras, y sólo de ellas, puede venir la emancipación de Rusia, en la cual la historia no atravesará sin dudas las mismas etapas sucesivas que en las naciones occidentales (Louis 1905a: 39).

Si bien no tiene citas explícitas, se desprende de la cita que Louis conocía seguramente los debates del socialismo ruso en torno al carácter de la revolución, negando la tesis de Plejanov sobre la conducción burguesa de la revolución rusa y acercándose en su última frase a algunas de las ideas que estaban en la base de la tesis de Trotsky (comparar con Ávila y Gaido 2015); una muestra del efecto radicalizante de la revolución de 1905 sobre los socialistas de muchos países.

Louis dedicará gran parte del libro a polemizar contra el socialismo reformista y el peligro de los ministerialismos y el compromiso. Esto no resulta sorprendente dado que era posiblemente el principal debate del socialismo de esos años. Trazaba una distinción tajante: O el socialismo se hará "puramente proletario", no se mezclará con otros movimientos políticos, se enfrentará con los "poseedores" (la burguesía) como un todo, o bien "sometido al idealismo de los precursores franceses y al estatismo de Lassalle" se transformará en el partido de las mejoras sociales, mezclará a los burgueses humanitarios con los trabajadores, y negará la ley histórica de la lucha de clases (Louis 1905a: 60-1). Le dará un peso determinante en el paso al reformismo a la penetración de intelectuales que se distinguen de los proletarios "por su modo de vida y sus lazos familiares" (Louis 1905a: 62), así como a los peligros de la práctica del parlamentarismo en la medida en que se haga en un espíritu de conciliación con otros partidos democráticos (Louis 1905a: 71-7). En ese sentido, establecerá una relación necesaria entre el surgimiento del sindicalismo 
Manuel Quiroga, Teorías del imperialismo y marxismo en el socialismo francés temprano: el caso de Paul Louis (18961907) / Theories of imperialism and Marxism in the early French socialism: the case of Paul Louis (1896-1907), Revista Izquierdas, 27, abril 2016, ISSN 0718-5049, pp. 342-367

revolucionario y los países "donde la alianza entre los socialistas de derecha y las fracciones burguesas democráticas se ha ejercido práctica y metódicamente" (Louis 1905a: 79). El escape a este método parlamentario llevaba al sindicalismo a encerrarse en un método corporativo: en la medida "que un grupo compacto de representantes socialistas se ligaba (...) a los gobiernos de concentración republicana, los sindicatos (...) repudian toda acción política (...) incitan a sus adherentes a no votar más" (Louis 1905a: 79); repudian toda tentativa de conquista del poder (Louis 1905a: 78)

Esto no sucedería en Austria y Alemania; sucedía en Francia e Italia, ligado especialmente a la existencia de las corrientes políticas radicales. Liga al radicalismo con la división de la propiedad agraria y un estadio donde la concentración capitalista no se despliega todavía plenamente; en cuanto ésta se realiza, tiende a desaparecer como fuerza política. Es una fuerza propia de una categoría "ni plenamente burguesa, ni todavía proletaria" (Louis 1905a: 99), y lo relaciona con una fuerza reaccionaria, que "mira hacia el pasado" intentando fútilmente revertir la concentración capitalista (Louis 1905a: 100 y 104). Los compromisos con esta capa eran uno de los mayores peligros para el proletariado: más allá de algunos puntos de coincidencia en cuanto a las libertades democráticas, era una capa que se volvía inherentemente conservadora cuando se planteaba alguna posibilidad de poner en peligro la propiedad privada (Louis 1905a: 107).

Louis también trataría de fijar un argumento de principios, pero a la vez bastante complejo, sobre la relación de los socialistas con la forma de gobierno republicana. Su planteo comienza planteando que el problema de la forma de gobierno "no tiene la misma importancia que en el Siglo XIX" ante la evidencia del sustrato económico común (capitalista) que las sustenta (Louis 1905a: 114-5). No obstante el régimen político no es indiferente al proletariado, y la forma de gobierno en el socialismo será una forma particular de República, donde "la igualdad en los derechos concretos y en la posesión de los útiles de trabajo comandará toda otra igualdad. Es la comunidad en su conjunto, de la célula a la aglomeración de células, de la Comuna a la Federación (...) la que gestiona sus asuntos" (Louis 1905a: 117-8).

En el capitalismo, mientras tanto, si a veces una forma de gobierno monárquica puede otorgar mayor cantidad de derechos cívicos y laborales a la vez que cercena derechos políticos (Louis1905a 119-120), en última instancia la necesidad de luchar por la república deriva de que en una monarquía, sea parlamentaria o absoluta, "la lucha de clases no se despliega allí jamás en toda su intensidad. O mejor, el antagonismo de clases está enmascarado por oposiciones secundarias" (Louis1905a: 121). No obstante, las posibilidades de aprovechar las ventajas tácticas de la República dependen de la existencia de un proletariado fuerte, consciente de sus propios intereses, de lo contrario será fácilmente presa del engaño de la clase dominante (Louis1905a: 122). La táctica de la burguesía de distintos países genera a su vez distintas relaciones del socialismo con la República: si en los países donde la monarquía se ha consolidado (por ejemplo Austria y Alemania), y los intereses de los terratenientes se han fundido con los de la burguesía, "la suerte de la República está subordinada a la del socialismo" y ha "pasado la hora (...) en la que una fracción de los poseedores (...) haría frente con la muchedumbre contra la realeza" (Louis1905a: 124-5), en Francia la burguesía utiliza "contra el peligro Cesarista" 
Manuel Quiroga, Teorías del imperialismo y marxismo en el socialismo francés temprano: el caso de Paul Louis (18961907) / Theories of imperialism and Marxism in the early French socialism: the case of Paul Louis (1896-1907), Revista Izquierdas, 27, abril 2016, ISSN 0718-5049, pp. 342-367

(refiriéndose seguramente a los movimientos antirrepublicanos de Boulanger y los anti Dreyffusards) la colaboración de clases, la cual "renueva lazos destruidos, y paraliza la potencia obrera" (Louis1905a: 128). Esto era un inteligente análisis de cómo la cuestión republicana gravitaba en Francia a favor de estrategias reformistas y de conciliación.

Sobre la huelga general, defenderá su progresividad como idea, atacando los argumentos más comunes para atacarla en el campo socialista. En particular la defenderá como una realidad utilizada por varias organizaciones con sentido más político o más insurreccional en distintos países (Bélgica e Italia especialmente), que tiene la virtud de ser fuertemente comprensible para el sentido común de un proletariado que ha obtenido mejoras a través de huelgas parciales y concibe entonces el enfrentamiento con la clase dominante bajo esta guisa, ganando rápidamente a grandes sectores del proletariado organizado en sindicatos para esta idea (Louis 1905a: 292-305). En relación a esto analizará la resolución del Congreso Internacional Socialista de Amsterdam de 1904, que defendía el uso de la huelga general como método para enfrentar a la reacción y obtener mayores derechos políticos, especialmente el sufragio universal. Planteará que la resolución es contradictoria: la misma acepta el uso de la huelga general por el proletariado "para obtener ventajas preliminares, ¡pero no para sacudir su verdadero yugo!” (Louis 1905a: 308).

Una reseña de esta obra en la International Socialist Review planteaba que el autor: "apoya la posición del ala de extrema izquierda del socialismo, denunciando en términos mesurados todas las alianzas con los partidos burgueses y se inclina hacia la extensión adicional de la huelga general" (ISR 1905: 61). A la luz de los debates en el socialismo francés, el planteo es totalmente justo; cabe destacar que su postura sobre la huelga general implicaba una ruptura con la ortodoxia Guesdista, que había propagandizado constantemente en contra de dicha táctica (Moss 1976: 138-139).

\section{Le Colonialisme: su influencia y el debate en el Congreso de Stuttgart}

Louis publicará en 1905 un breve opúsculo titulado Le Colonialisme, que adquiriría gran difusión.

En cuanto al origen económico del colonialismo, Louis plantearía: "La clase poseedora industrial y comerciante- busca, sea mercados para sus productos, sea una colocación para sus reservas de dinero, sea nuevas fuentes de explotación y riqueza" (Louis 1905b: 21). No obstante, al analizar el caso de las colonias establecidas para monopolizar mediante el trabajo indígena una materia preciosa (por ejemplo el Congo), plantea que tenderían a desaparecer progresivamente ante la colonización mercantil, que sería totalmente dominante (Louis 1905b: 29). La contradicción entre "la concurrencia y el extremo individualismo de los empresarios" implica que cada uno quiere sacar el máximo provecho de su maquinaria y sus salarios, llevando a la sobreproducción, que se busca superar mediante el colonialismo, "última carta del capitalismo" (Louis 1905b: 32-34). Esto implicaba volver simplemente a su vieja tesis sobre la búsqueda de mercados, dejando de lado sus desarrollos de la etapa anterior. 
Manuel Quiroga, Teorías del imperialismo y marxismo en el socialismo francés temprano: el caso de Paul Louis (18961907) / Theories of imperialism and Marxism in the early French socialism: the case of Paul Louis (1896-1907), Revista Izquierdas, 27, abril 2016, ISSN 0718-5049, pp. 342-367

El libro se dedicará en gran parte a ofrecer argumentos propagandísticos contra la colonización: El carácter necesariamente guerrero de las empresas coloniales, el conjunto de las violencias hacia los indígenas, incluyendo trabajo forzado, masacres, expropiaciones brutales por causas de utilidad privada e impuestos exorbitantes (Louis 1905: 60-69), y cómo todo esto provoca insurrecciones permanentes en las colonias que sólo pueden ser detenidas mediante la aniquilación (Louis 1905b: 46). Este énfasis probablemente también tenía que ver con la situación en Francia ese año, donde habían salido a la luz toda una serie de escándalos vinculados con maltratos a los indígenas en las colonias; durante todo 1905 y hasta las elecciones de 1906, el periódico socialista L'Humanité había desarrollado una fuerte campaña contra la "barbarie colonial" en Congo, el África Francesa, las Antillas y Guyana dirigida por Rouanet (Haupt y Rebérioux 1963: 16).

Le dará importancia también a la cuestión del costo de las colonias, destacando que los beneficios que estas pudieran llegar a ofrecer alcanzan sólo a una pequeña parte de la población, y que la mayor parte de la carga que implicaba sostener las colonias estaba sobre las espaldas del proletariado; sobre el comercio colonial, enfatizará como las metrópolis después de gastar mucho en abrir el dominio de un espacio, no pueden controlar efectivamente su comercio (el imperialismo sería una respuesta a esto); y como las conquistas coloniales multiplican las chances de conflicto militar entre potencias (Louis 1905b: capítulos 4, 6 y 7).

Por último, analizará las consecuencias sociales del colonialismo y su importancia para la política proletaria. Su tesis es que agudiza las contradicciones de clase: Incrementa sin cesar el número de proletarios, por un lado, a partir de las quiebras de empresas menores, y, por otro, a partir de la proletarización de las poblaciones coloniales. A su vez, plantea cómo las expediciones y conquistas de la burguesía han "disminuido su prestigio moral y sobreexcitado el desprecio de las masas" (Louis 1905b: 108). Si bien era imposible detener el colonialismo, dado que si los socialistas y el proletariado fueran ya suficientemente fuertes para detenerlo, significaría que serían ya dueños del Estado, la agitación anti colonial servía como un instrumento de propaganda y aumentaba la autoridad del proletariado en la medida que "manifiesta su solidaridad efectiva con los indígenas anexados, reivindicando para ellos derechos esenciales" (Louis 1905b:109).

Concluye:

Es considerando (...) sus efectos directos e indirectos que se aprende a apreciar la solidaridad de intereses, que funden en una masa común, a todos los sufrientes, todos los humillados del mundo, a pesar de las diferencias de raza, de color y de lengua (Louis 1905b: 110).

En síntesis, en términos del análisis económico, esta obra implica en mi opinión un retroceso frente a sus desarrollos de la etapa anterior, volviendo a una explicación económica más básica. El libro fue sobre todo una pieza de propaganda que "retoma con fuerza los argumentos habituales contra la colonización" (Haupt y Rebérioux 1963: 15). Los aspectos más originales en el contexto político del momento eran su énfasis en la suerte de los pueblos colonizados, su tendencia inevitable a la insurrección y la necesidad de vincular solidariamente los proletarios de los países avanzados de Europa con los de los países colonizados.

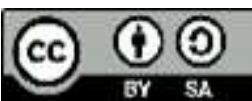


Manuel Quiroga, Teorías del imperialismo y marxismo en el socialismo francés temprano: el caso de Paul Louis (18961907) / Theories of imperialism and Marxism in the early French socialism: the case of Paul Louis (1896-1907), Revista Izquierdas, 27, abril 2016, ISSN 0718-5049, pp. 342-367

El trabajo fue elaborado mientras se completaba la unificación de las tendencias socialistas en la SFIO. Probablemente, la necesidad de presentar una posición que pudiera representar al partido unificado llevó a Louis a enfatizar los argumentos más propagandísticos y comunes contra el colonialismo, moderando sus propios planteos más radicales. Un resumen de este libro aparecería publicado en le Socialiste, y aparecería después como reporte en el congreso de 1907 en Nancy de la SFIO, junto con un artículo de Rouanet sobre la situación de los indígenas, donde sería adoptado ¡sin discusión!, lo que Haupt y Rebérioux han presentado como una prueba de que Francia constituía una excepción al creciente interés en el colonialismo en la Segunda Internacional en dicho año (Haupt y Rebérioux 1963: 17).

A su vez, un reporte similar escrito por Paul Louis fue enviado al Congreso de la Internacional Socialista en Stuttgart, junto con un artículo del holandés Van Kol. Van Kol era un apologista del colonialismo, que en el debate dentro del Congreso, produjo una resolución que planteaba en su parte final: "El Congreso por tanto no rechaza en principio toda política colonial. Bajo un régimen socialista, la colonización podría ser una fuerza para la civilización" (Day y Gaido 2012: 25). Esto acompañado de varios argumentos que sostenían la necesidad de la tutela de los pueblos civilizados sobre los "salvajes". Varios delegados, liderados por Kautsky, atacaron la idea de que pudiera existir una "política colonial socialista", prevaleciendo finalmente en la votación, pero sólo por una pequeña diferencia alcanzada mediante el voto combinado de las naciones pequeñas, mientras que la mayor parte de la delegación alemana (incluyendo a Bernstein) había apoyado la propuesta de Van Kol (Day y Gaido 2012: 28-29). El reporte de Louis, más allá de su carácter escasamente original, tendió a entroncar con la posición de condena a la expansión colonial que terminó prevaleciendo en la resolución final, una victoria de la izquierda de la Social Democracia europea que reflejaba, a su vez, la fuerza que habían adquirido las tendencias pro coloniales dentro del socialismo internacional.

\section{Conclusión}

Hemos reseñado las etapas por las que pasó el pensamiento de Louis sobre el imperialismo y el colonialismo y algunos desplazamientos en sus posiciones: de ilusiones sobre el carácter pacífico de la colonización británica y norteamericana a su desaparición; del simple planteo de la búsqueda de "mercados" para la sobreproducción a su relacionamiento con el proteccionismo y los trusts; de los "grupos de especuladores" como beneficiarios de la colonización al conjunto de la burguesía; del imperialismo como federación aduanera al imperialismo como fase; y finalmente, el retroceso a todos los argumentos más comunes en Le Colonialisme. Hemos relacionado estas transformaciones con las disputas de tendencias en el socialismo francés, viendo cómo en un momento de relativa "unidad" del conjunto de las tendencias su análisis tendía a presentar más características propias del "sentido común" republicano; cómo en un momento de radicalización de Guesdistas y Blanquistas, produjo un análisis del imperialismo como fase; y cómo en 1905, después de la unificación partidaria, retrocedió a una serie de lugares comunes en su análisis, que ofrecieron al 
Manuel Quiroga, Teorías del imperialismo y marxismo en el socialismo francés temprano: el caso de Paul Louis (18961907) / Theories of imperialism and Marxism in the early French socialism: the case of Paul Louis (1896-1907), Revista Izquierdas, 27, abril 2016, ISSN 0718-5049, pp. 342-367

partido unificado del SFIO una posición doctrinaria aceptable para la mayor parte de las tendencias. A su vez, hemos visto cómo intentó desarrollar a partir de 1905 una posición política revolucionaria que combatiera al reformismo y a las ideas anti políticas del sindicalismo, a partir de una revalorización del instrumento de la huelga general y un repudio al reformismo y a la participación ministerial que permitiera tender puentes con estos últimos, los cuales dominaban las organizaciones sindicales de Francia.

Entre las lagunas de Louis, podemos citar la escasa discusión sobre tácticas para combatir concretamente el colonialismo, así como el no haber abordado seriamente el problema de las colonias "blancas" de Francia, tales como Argelia (Ageron 1963: 22).

No obstante, Louis tuvo el mérito de estudiar los fundamentos económicos del imperialismo, así como de tener una postura claramente anti racista y de solidaridad con los pueblos colonizados. Sus análisis fueron probablemente los mejores en francés en esa época, y ayudaron a sentar las bases de análisis posteriores más articulados.

\section{Bibliografía y documentos}

Ageron, Charles-Robert (1963), 'Jaurès et les socialistes français devant la question algérienne (de 1895 à 1914) ' en Le Mouvement Social, No. 42 (Jan. - Mar., 1963), pp. 3-29, París, Editions L'Atelier.

Andreucci, F. (1988), Socialdemocrazia e imperialismo: I marxisti tedeschi e la política mondiale, 1884-1914, Roma, Editori Riuniti.

Ávila, Paula y Gaido, Daniel (2015) "Fuerzas motrices y perspectivas de la revolución rusa, Karl Kautsky, 1906”, en Revista Izquierdas, N 24 pp. 246-283, Instituto de Estudios Avanzados de la Universidad de Santiago de Chile.

Bédarida, François (1974), 'Perspectives sur le Mouvement ouvrier et l'impérialisme en France au temps de la conquête coloniale' en Le Mouvement Social, No. 86 (Jan. - Mar., 1974), pp. 25-42, París, Editions L'Atelier.

Brewer, Anthony (1980), Marxist Theories of Imperialism: A Critical Survey. Boston: Routledge \& Kegan Paul.

Cole, Douglas Howard (1975), Historia del Pensamiento Socialista, tomo III, México: Fondo de Cultura Económica.

Day, Richard B. y Gaido, Daniel (2012), Discovering Imperialism: Social Democracy to World War I, Leiden: Brill.

DBMOF (2007) -Dictionnaire biographique du mouvement ouvrier français-, Vol. III, entrada "Paul-Louis", Paris, Maitron/Editions de l'Atelier.

Haupt, Georges y Rebérioux, Madeleine (1963), 'L'attitude de l'Internationale' en Le Mouvement Social, No. 45 (Oct. - Dec., 1963), pp. 7-37, París, Editions L’Atelier.

Hilferding, Rudolf (1903), "Der Funktionswechsel des Schutzzolles: Tendenz der modernen Handelspolitik", en Die nеие Zeit, 21.1902-1903, 2. Bd. (1903), H. 35, S. 274-281.

ISR (International Socialist Review) (1905), Volumen VI, Julio 1905, №1.

Joll, James (1976), La Segunda Internacional, 1889-1914, Barcelona : Icaria. 
Manuel Quiroga, Teorías del imperialismo y marxismo en el socialismo francés temprano: el caso de Paul Louis (18961907) / Theories of imperialism and Marxism in the early French socialism: the case of Paul Louis (1896-1907), Revista Izquierdas, 27, abril 2016, ISSN 0718-5049, pp. 342-367

Kautsky, Karl (1900), 'Deutschland, England und die Weltpolitik', Vorwärts, 105 and 107 (8 and 10 May).

Lenin (1964), “Notebooks on imperialism, Vol. 39, Cuaderno $\gamma$ (gamma): Paul Louis", en Collected works, Moscú: Editorial Progreso.

Lenin, Vladimir I. 1970 [1916], Imperialism, the Highest Stage of Capitalism: A Popular Outline, Peking: Foreign Languages Press.

Louis, Paul (1896), 'Les Résultats du système Méline', en La Revue Socialiste, N 140, Aout: 129169.

Louis (1897a), 'La Colonisation sous la troisième République', en La Revue Socialiste, $\mathrm{N}^{\circ} 145$, Janvier 1897: 24-38.

Louis (1897b), 'La Colonisation sous la troisième République (suite et fin)', en La Revue Socialiste, $\mathrm{N}^{\circ}$ 146, Fevrier 1897: 155-173.

Louis (1898a), 'A propos de la Guerre Hispano-Américaine' en La Revue Socialiste $\mathrm{N}^{\circ}$ 161, Mai: 604-619.

Louis (1898b), 'La Fédération anglo-saxonne' en La Revue Socialiste, № 162, Juin: 739-743.

Louis (1898c), 'Désarmement?' en La Revue Socialiste, № 165, Septembre: 257-262.

Louis (1898d), 'La situation internationale' en La Revue Socialiste $\mathrm{N}^{\circ}$ 166, Octobre: 393-417.

Louis (1899a), 'L'Accord Franco-Italien' en La Revue Socialiste ${ }^{\circ}$ 169, Janvier: 35-40.

Louis (1899b), 'L'Impérialisme Anglo-Saxon' en La Revue Socialiste N ${ }^{\circ}$ 171, Mars: 257-273. Versión inglesa usada en Gaido y Day (2012: 129-146).

Louis (1899c), 'Le Socialisme et l'expansion coloniale contemporaine' en La Revue Socialiste $\mathrm{N}^{\circ}$ 173, Mai: 553-572

Louis (1899d), 'La Conférence de La Haye’ en La Revue Socialiste N 174, Juin: 658-662.

Louis (1899e), 'La Question Sud-Africaine' en La Revue Socialiste N 175, Juillet: 59-63.

Louis (1899f), 'La Grandeur des Etats-Unis 'en La Revue Socialiste N$^{\circ} 176$, Aout: 181-199.

Louis (1899g), 'L'Extrême-Orient', en La Revue Socialiste Nº 178, Octobre: 398-414.

Louis (1899h), 'La Crise Sud-Africaine' en La Revue Socialiste $\mathrm{N}^{\circ}$ 179, Novembre: 541-7.

Louis (1900a), 'Le plus grande Allemagne', en La Revue Socialiste № 181 Janvier 96-101

Louis (1900b), 'Sur les Evénements de Chine', en La Revue Socialiste № 188, Aout: 196-201.

Louis (1900c), 'L'Evolution économique du Globe' en La Revue Socialiste ${ }^{\circ}$ 180, Decembre: 702-713.

Louis (1900d), 'L'Impérialisme (Angleterre, Etats-Unis)', La Revue Blanche, 23, SeptemberDecember: 145-8. Versión inglesa usada en Gaido y Day (2012: 147-154).

Louis (1901a), 'La colonisation contemporaine', La Revue Blanche, 24 (1 Fevrier): 161-72.

Louis (1903a), 'Les bases de l'impérialisme', La Renaissance Latine, 3, 2 (15 Septembre):644-78.

Louis (1903b), Les Etapes du socialisme, Paris: Bibliothèque -Charpentier.

Louis (1904), 'Essai sur l'impérialisme', Le Mercure de France, 50, 172, (April): 100-14.

Louis (1905a), L'Avenir du Socialisme, Paris: Bibliothèque -Charpentier.

Louis (1905b), Le colonialisme, Paris: Société nouvelle de librairie et d'édition.

Luxemburg, Rosa, 1951 [1913], La acumulación del capital, México: Grijalbo.

Malon, Benoît (1892), Le Socialisme Intégral, tomo I, París: Librairie de La Revue Socialiste.

Moss, Bernard H. (1976), The Origins of the French Labor Movement 1830-1914: The Socialism of Skilled Workers, Berkeley and Los Angeles: University of California Press. 
Manuel Quiroga, Teorías del imperialismo y marxismo en el socialismo francés temprano: el caso de Paul Louis (1896-

1907) / Theories of imperialism and Marxism in the early French socialism: the case of Paul Louis (1896-1907), Revista Izquierdas, 27, abril 2016, ISSN 0718-5049, pp. 342-367

Noland, Aaron (1956), The Founding of the French Socialist Party (1893-1905), Cambridge: Harvard University Press.

Rebérioux, Madeleine (1964), 'La gauche socialiste française: La Guerre Sociale et Le Mouvement Socialiste face au problème colonial’, en Le Mouvement Social, No. 46, (Jan.-Mar. 1964), pp. 91103, París: Editions L'Atelier.

Rebérioux (1968), 'Les tendances hostiles à l'Etat dans la S.F.I.O. (1905-1914)', en Le Mouvement Social, No. 65 (Oct. - Dec., 1968), pp. 21-37, París: Editions L’Atelier.

Steenson, Gary P. (1991), After Marx, before Lenin. Marxism and socialist working-class parties in Europe, 1884-1914, Pittsburgh: University of Pittsburgh Press.

Thomas, R. (1960), 'La politique socialiste et le problème colonial de 1905 à 1920' en Revue française d'histoire d'outre-mer, tome 47, n¹67, deuxième trimestre 1960, pp. 213-245, París.

Tudor H. and J.M. Tudor (eds.) (1988), Marxism and Social Democracy: The Revisionist Debate 1896-1898, Cambridge University Press.

Willard, Claude (1965), Les Guesdistes, Paris, Éditions Sociales. 